\title{
PLS and OPLS Discriminatory Analyses on Political Sustainability in Taiwan
}

\author{
Shianghau $\mathrm{Wu}^{1, *}$ and Jiannjong Guo ${ }^{2}$ \\ 1 School of Business, Macau University of Science and Technology, Macau 999078, China \\ 2 Graduate Institute of China Studies, Tamkang University, New Taipei City 25137, Taiwan; \\ jj03082011@gmail.com \\ * Correspondence: shwu@must.edu.mo; Tel.: +853-8897-2399
}

Received: 19 October 2017; Accepted: 25 December 2017; Published: 2 January 2018

\begin{abstract}
Political sustainability relates to successful governance. The general public's satisfaction is vital to political sustainability. In this paper, we propose to use the general public's satisfaction as the proxy and utilize the partial least squares discriminatory (PLS-DA) model and orthogonal partial least squares discriminatory (OPLS-DA) model to explore the factors that affect political sustainability in Taiwan. The results of the PLS-DA and OPLS-DA models vindicate that the satisfaction with the integrity performance of the central government, the satisfaction with the central government's modus operandi on food safety, and the satisfaction with the central government's policies on the twelve years primary education reform influence the Taiwanese civilians' satisfaction with the central government, which is closely related to political sustainability. This offers us the insights on political sustainability in Taiwan.
\end{abstract}

Keywords: political sustainability; PLS-DA model; OPLS-DA model

\section{Introduction}

Political sustainability relates to successful governance. The general public's satisfaction affects political sustainability. Taiwan has been renowned for its growth with equity experience through development-oriented governance. Its governance mechanism was implemented by a coherent, competent and merit-based economic bureaucracy. However, some scholars have argued that whether such a growth experience is valid in Taiwan [1]. Taiwan's experience can offer an example of political sustainability under circumstances of the changing public opinion. Taiwan's experience can be of interest to other governments with the same governance mechanism. In this paper, we propose to utilize the PLS-DA and OPLS-DA models to explore the factors that affect the satisfaction of the general public. The structure of the paper starts with the literature review of political sustainability, and the relationship between the citizens' satisfaction and political sustainability, and follows with the methodology. The study analyzed and drew conclusions from the research results.

\section{Literature Review}

\subsection{Political Sustainability}

The concept of political sustainability relates to institutional adaption and selection. According to Borras (2004), the meaning of political sustainability stems from the good governance concept and has a close relationship with technological and economic progress [2]. Schmitz and Cassiolato (1992) suggest that political sustainability requires contestability, which means the supply of public goods should not be controlled by the government [3]. Patashnik (2003) states that the long period political sustainability is based on well-functioning political institutions and affirmative policy feedback effects [4]. Navarro-Galera (2017) mentions that some international organizations put more 
emphasis on the requirements for government to take good governance measures to achieve political sustainability [5].

The other aspect of political sustainability relates to the policy formulation process. Patashnik (2008) states that public interests policy is based on the reconfiguration of political dynamics [6]. In order to achieve the sustainability of public interests policy, the monopoly of governmental power and old institutions should be curtailed and policy feedback effects should be created. However, the institutional change cannot ensure successful policy reform. This is mainly because the policy change would fall into an incomplete situation and has the possibility to be reversed.

Ayre and Callway (2005) stipulate the elements of the good governance for sustainability and the three pillars of political sustainability, including environmental governance, economic governance and society participation and engagement [7].

Political sustainability also relates to the sustainable development model elaborated by Holden et al. (2016), which stipulates that a policy that results in sustainable development is under the constraint of equity, needs and limits, where equity means to ensure social equity, needs means to satisfy human needs, and limits means to respect environmental limits [8].

As far as the measurable indicators of the political sustainability are concerned, Filho et al. (2016) elucidate that some indicators are comprised of the existence of social justice and accepted ethical values, as well as attention to economic and ecological values of natural resources, and the degree of recognition by the citizens [9].

\subsection{Political Sustainability and Citizens' Satisfaction}

Weaver et al. (1997) states that the concepts of the sustainable development are closely related to public administration principles. In order to streamline sustainable development, it needs a growing economy with governmental structure transformation, equally shared benefits, civil society, human rights protection, environmental protection and maintenance of lifestyle [10].

Foret et al. (2014) points out that the development of each place hinges on the cooperation among the public administration, entrepreneurs and citizens [11]. Citizens Relationship Management (CiRM) is a strategy that would optimize the relationship between the government and citizens and encourage citizen participation [12]. As for the important element of the sustainable development policies, Fournier (2008) elaborates that citizen participation and democracy are vital to the fair resources allocation and the redefinition of economic relations and political identities [13]. Holzer and Kloby (2005) note that citizen participation in governmental performance measurement enables the facilitation of the policy decision making process [14]. Reddel and Woolcock (2004) also mention that the civil engagement relates to the civilians' participation in the policy decision making process, while the connection among the civil society, private sector and the government is vital to the participatory governance [15]. Li et al. (2016) find the civilians perceptions and responses are essential inputs in urban decision-making and management, which are also the value of bottom-up participatory approaches for urban sustainability transitions [16]. It implies that the pivotal role of citizen participation and satisfaction in the realm of the political sustainability. Demke and Moilanen (2011) elaborate the good governance value parameters which involve administrative reform public policy planning aiming at specific social-economic targets include governmental transparency, equitability and inclusiveness for any individual and legal entity, responsiveness, accountability, rule of law, civilian participation, and consensus among civilians and the government [17].

With regard to the measurement of the levels of sustainable policies, some scholars have shed the light on the determination of indicators. Holden et al. (2017) stipulates that the indicators of sustainable development should stick to the constraints and moral imperatives of needs, equity and limits and six sustainable development themes, which include eradicating human poverty, enhancing human capabilities, ensuring participation, ensuring fair distribution, mitigating climate change and safeguarding biosphere integrity [8]. 
In order to evaluate political sustainability in Taiwan, the study adopted the sustainable development indicators and good governance value parameters to measure the effects of sustainable policies. The study concluded the indicators as the following aspects: (i) economic performance; (ii) future expectations; (iii) educational reform; (iv) food safety; (v) the effects of Sunflower Movement; (vi) integrity. As for the relationship between our indicators and the constraints of sustainable development by Holden et al. (2017), the indicators of economic performance, future expectations, food safety and educational reform belong to the realm of needs. The effects of Sunflower Movement and integrity belong to the realm of equity.

\subsection{Taiwanese Citizens' Satisfaction}

According to the literature, the Taiwanese people's satisfaction with the government relates to the subsequent aspects:

(i) Economic performance: In Taiwan, economics is historically a left-right issue [18]. The economic development in Taiwan was once taken as the miracle in East Asia. Taiwan's economic development was due to the expansion of exports within the years of the 1970s and 1980s. However, owing to the decay of the Original Equipment Manufacturer (OEM) and the Original Design Manufacturer (ODM) orders, the surplus outflow of the industries, passive research and development, the depleted advanced industries and entrepreneurship, deficient financial mediation, and excess economic dependence on mainland China, Taiwan has become stagnated [19]. As a result of the withering economic conditions, Taiwanese voters raised concerns regarding the economic performance which has impacted on the satisfaction level with the government. Ayers and Callway (2005) elucidate the goals for successful economic problem solving in the realm of successful governance. These goals include domestic poverty alleviation, enough food supply, primary education, gender equality, health problems alleviation, clean drinking water supply, sustainable development, solving the side effects of international free trade and handling governmental debts [7].

(ii) Future expectation: The relationship between the subjective and objective measures of governmental performance has been the analysis focus of the public administration [20]. Although some studies raise doubts regarding the voters survey as the proxy for evaluating the governmental performance [21], recent studies have indicated that voters would have correct perceptions for some local government services [22]. As for the relationship between the long run expectation of voters and their satisfaction with the government, Van Ryzin (2007) stipulates the model that citizens' future expectations affect their trust, perceived performance and evaluation to the governmental performance [23].

(iii) Educational reform: Because of the dynamic of the society and domestic politics, Taiwan has set out an educational reform plan. The educational reform took the form of a curriculum reform. The Grade 1-9 Integrated Curriculum solely made guidelines for schools and enabled primary and secondary schools to have the flexibility to determine their textbooks and study plans. However, the educational reform has raised criticism and complaints from teachers attributable to their inability to respond to the curriculum changes [24]. Besides, teachers did not have detailed information regarding the reform and cannot persuade parents to support the reform. Therefore, the education reform has resulted in opposition and discontent among both teachers and parents [25].

(iv) Food safety: The food safety scandal has raised general public concern since the prohibited usage of food additives in 2011. The Taiwan Food and Drug Administration (TFDA) determined that two corporations used DEHP (di(2-ethylhexyl)phthalate) and DiNP(Di-iso-nonyl Phthalate) for vegetable oil in evaporation agents and distributed them to major Taiwanese food manufacturers [26]. Tsai et al. (2016) investigated the connection between the DEHP tainted food and the urinary organ performance in kids and showed that the intake of DEHP tainted food would have the potential risk for microalbuminuria. The food safety scandal has become one of the key considerations of Taiwanese voters and relates to their satisfaction with the government [27]. 
(v) Sunflower Movement: The "Sunflower Movement" in 2013 was the tipping point for the cross-strait economic policy change in Taiwan. The governing Nationalist Party (KMT) decided to facilitate the legislative process of the Cross-Strait Services Trade Agreement (CSSTA) after the agreements from two quasi-state agencies, the Straits Exchange Foundation and the Association for Relations Across the Taiwan Strait, the counterpart of the Mainland China in 2013, while some non-governmental organization (NGO) leaders worried that the CSSTA would enable more Mainland penetration into Taiwan's economy and intended to sabotage the legislative process. The protesters then unlawfully occupied the Legislative Yuan and made the whole legislative process in stalemate and stalled. The aftermath of the "Sunflower Movement" has several side effects. The movement was deemed as the main reason for the Democratic Progressive Party to win the landslide victory in the 2014 election [28,29].

(vi) Integrity: Sustainability is an obviously normative concept and includes the particular moral attitude to the future. It relates to the moral responsibility to the future generations. The outcome assessment of the political sustainability is based on concerns about justice [30]. Governmental integrity behavior relates to the moral issue of the political sustainability. Joshi et al. (2015) determine the governance variables related to the sustainable development. The governance variables include the security index, the capacity index and the inclusion index. The governmental integrity behavior is evaluated as the corruption level. In light of the previous literature, the study used governmental integrity behavior as one of the factors which affect political sustainability [31].

\section{Research Method}

\subsection{Research Process}

The flowchart of the study was shown as Figure 1. In the beginning, the study obtained the surveyed data which can be downloaded for academic research usage. Then the study attempted to construct the model about the Taiwanese people's satisfaction with the government according to the literature. Our methodology belongs to data mining methodology. Data mining is a set of techniques for analyzing and describing the structured data, including finding patterns in large data sets. Related to work in the study [32], the goal of the study aimed at discovering the knowledge in our data. By means of the PLS-DA and OPLS-DA models analysis, the research model is finally determined. The study also analyzes the significant variables in the model.

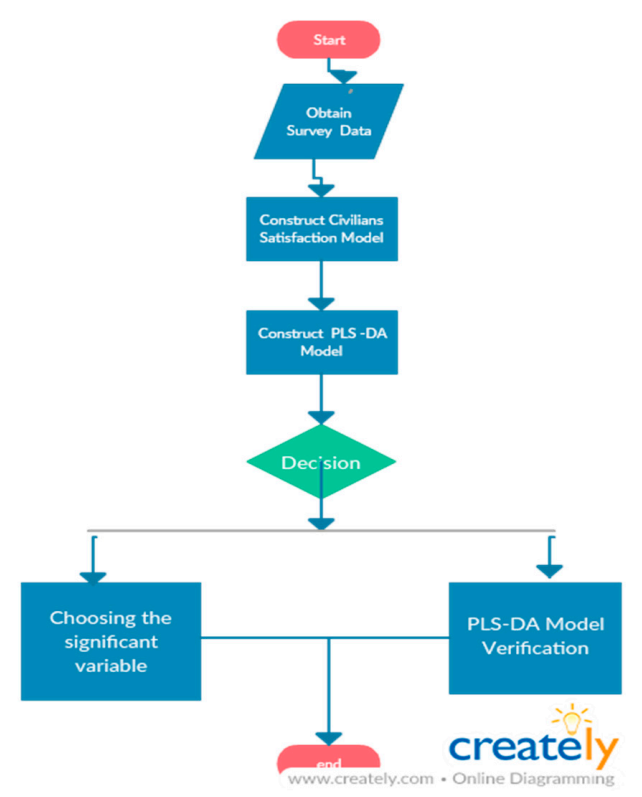

Figure 1. Visualizing the flow chart. 


\subsection{PLS-DA Model}

The study utilized the "DiscriMiner" and "MixOmics" packages to calculate the partial least square discriminatory (PLS-DA) model. The goal of the PLS-DA model is to identify the key variables which can better explain the satisfaction level of Taiwanese people. The PLS-DA model utilizes the dimension reduction to configure the data into fewer dimensions following by a leave-one-out based testing model. The results of the testing model include $\mathrm{R}$-square $\left(\mathrm{R}^{2}\right)$ scores indicating the explained variance and $\mathrm{Q}$-square $\left(\mathrm{Q}^{2}\right)$ indicating the predictive variance of fit [33]. The method extracts the predictor variable and indicates its importance in explaining the response variable. The model also offers the variable on projection (VIP) scores to state the characteristic of highest importance in explaining the relationship among variables. PLS-DA is the multivariate model which allows the dataset with highly correlated variables.

\subsection{Sample Data and Variables}

Based on the questionnaire survey of Taiwan's Election and Democratization Study (TEDS) conducted by National Chengchi University (NCCU) on the local election of Taiwan in 2014, we analyzed the satisfaction of Taiwanese people toward the government by using the collected questionnaire data. The data set consists of interview responses from three major cities: Taipei, Taichung and Kaohsiung. The TEDS survey successfully made 1133 survey responds in Taipei, 1141 in Taichung and 1174 in Kaohsiung. The survey used the "Demographic Factbook 2014" (published by Ministry of the Interior) as the basis of the population group. In order to make the successful independent samples meet the population structure, the survey used "sex", "age", and "education" to proceed the statistic testing and raking weighting method. By means of samples testing and weighting, the structure of the whole sample is not different from the population [34]. The variables designed for the Taiwanese people's satisfaction model include "satisfaction with the central government in these three years" (h1, the dependent variable), "the satisfaction with the integrity performance of the central government" (h2), "evaluation of Taiwan's current economic condition as compared with a year ago" (h3), "evaluation of Taiwan's economic condition one year after" (h4), "evaluation of your household's economic condition as compared with a year ago" (h5), "evaluation of your home's economic condition one year after" (h6), "satisfaction with the central government's modus operandi on food safety" (h7), "satisfaction with the central government's policies on the twelve years primary education reform" (h8) and "the satisfaction level with the government's reaction with the Sunflower Movement" (h9). The study chose the Taipei city data as the sample data. This is mainly owing to the fact that Taipei city is the capital city and plays the role as the economic center in Taiwan. The descriptive statistics of the dataset included 821 survey responses after filtering the ineffective survey responses. The descriptive statistics of the data was shown on Table 1 . The satisfaction level (h1, $\mathrm{h} 2, \mathrm{~h} 7, \mathrm{~h} 8, \mathrm{~h} 9$ ) ranges from 1 (the lowest) to 4 (the highest), while that of h3, h4, h5 and h6 ranges from 1 (the lowest) to 3 (the highest). The study's evaluation of the economic performance was measured by means of "the evaluation of Taiwan's current economic condition as compared with a year ago" (h3), "the evaluation of your household's economic condition as compared with a year ago" (h5), "the evaluation of your home's economic condition one year after" (h6). The evaluation of the future expectation was measured by means of "the evaluation of Taiwan's economic condition one year after" (h4). The evaluation of the educational reform was measured by means of "satisfaction with the central government's policies on the twelve years primary education reform" (h8). The evaluation of the Sunflower Movement was measured by means of "the satisfaction level with the government's reaction with the Sunflower Movement" (h9). The evaluation of the governmental integrity behavior was measured by "the satisfaction with the integrity performance of the central government" (h2). Finally, the evaluation of food safety was measured by the "satisfaction with the central government's modus operandi on food safety" (h7). 
Table 1. The descriptive statistics of the data.

\begin{tabular}{ccccc}
\hline Variable & Mean & Std & Minimum & Maximum \\
\hline h1 & 3.14 & 0.752 & 1.00 & 4.00 \\
h2 & 2.96 & 0.832 & 1.00 & 4.00 \\
h3 & 2.04 & 0.907 & 1.00 & 3.00 \\
h4 & 2.38 & 0.787 & 1.00 & 3.00 \\
h5 & 2.55 & 0.754 & 1.00 & 3.00 \\
h6 & 2.60 & 0.641 & 1.00 & 3.00 \\
h7 & 3.58 & 0.654 & 1.00 & 4.00 \\
h8 & 3.37 & 0.708 & 1.00 & 4.00 \\
h9 & 1.93 & 0.761 & 1.00 & 4.00 \\
\hline
\end{tabular}

\subsection{PLS-DA Principal Component Analysis}

The study used h1 as the dependent variable and h2 to h9 as independent variables to construct the PLS-DA model. In the principal component analysis, the PLS package of R language approximate the $X$ matrix by the first principal components (PCs), obtained from the singular value decomposition as follows [35],

$$
X=\tilde{X}_{(a)}+\varepsilon_{X}=\left(U_{(a)} D_{(a)}\right) V_{(a)}^{T}+\varepsilon_{X}=T_{(a)} P_{(a)}^{T}+\varepsilon_{X}
$$

The PLS package then regress $Y$ on the scores and the regression coefficients are shown as follows,

$$
B=P\left(T^{T} T\right)^{-1} T^{T} Y=V D^{-1} U^{T} Y
$$

According to the PLS regression model, the latent variables can be obtained. The PLS-DA principal analysis results were shown as Table 2 .

Table 2. Principal component analysis of the partial least squares (PLS) model.

\begin{tabular}{ccccccccc}
\hline & 1 Comps & 2 Comps & 3 Comps & 4 Comps & 5 Comps & 6 Comps & 7 Comps & 8 Comps \\
\hline$X$ & 26.29 & 46.75 & 57.76 & 67.71 & 77.44 & 85.97 & 93.79 & 100 \\
h1 & 40.34 & 41.32 & 41.58 & 41.62 & 41.72 & 43.37 & 44.55 & 45.49 \\
\hline
\end{tabular}

It can be induced that 7 components can explain over $90 \%$ of the independent variables, and all independent variables can explain $45.49 \%$ of h1. According to Figure 2, the independent variable h2, h7, h8 (variable no. 1, 6, 7 on Figure 1) have the positive relationship with h1.

h1

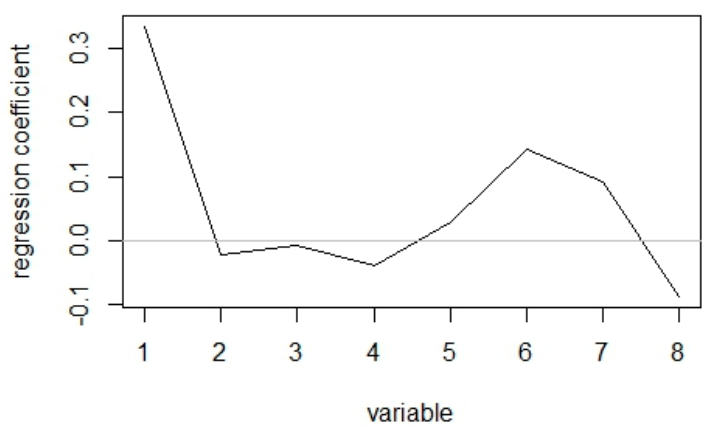

Figure 2. Regression coefficients of the principal component analysis. 
The study also used the PLS package to choose the components of independent variables according to the RMSEP value from the principal component analysis and obtained the recommended value of the components as 1 from Figure 3.

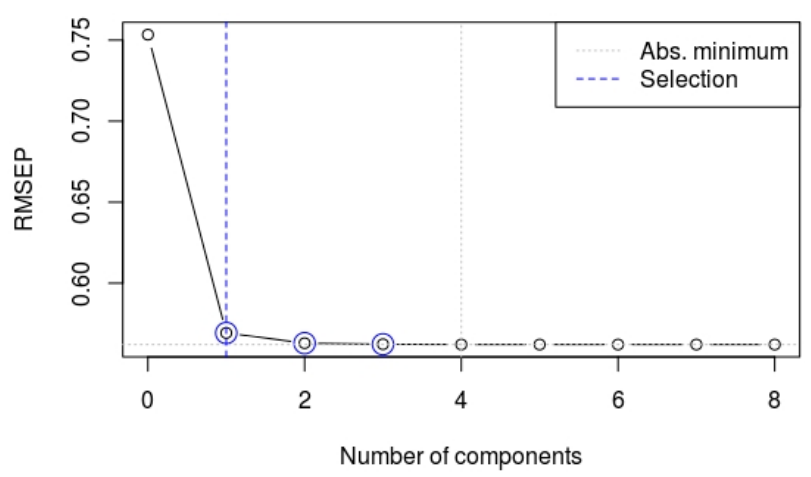

Figure 3. Components choosing of the principal component analysis.

\subsection{PLS-DA Model}

The study used the DiscriMiner software package to construct the PLS-DA model and OPLS-DA model. The PLS-DA model is the extension of the PLS regression by a linear discriminant analysis to be used for the classification process. For each response variable $y_{k}$, a regression model can be expressed as [36]:

$$
y_{k}=\sum_{h=1}^{m}\left(X w_{h}^{*}\right) c_{h}+e=X W^{*} c+e
$$

where $w_{h}{ }^{*}$ is a p-dimension vector, and $p$ is the number of parameters containing the weights given to each original variable in the $k$-th component, and $c_{h}$ is the regression coefficient of $y_{k}$ on the $h$-th $X$ component variable.

The study constructed the PLS-DA model to make the classification analysis and the results were shown as follows. Since the recommended value of components was 1 according to Figure 3, the study used 2 as the value of components to analyze the model in order to obtain more information.

According to Table 3, the cumulative $\mathrm{R}^{2}$ value of the independent variables (R2Xcum) was 0.410 , while the cumulative $R^{2}$ value of the dependent variable (R2Ycum) was 0.167 . It means the model can explain $16.7 \%$ of dependent variable. Figure 4 showed the variables plot of the PLS-DA model. It indicated that $\mathrm{h} 3, \mathrm{~h} 4, \mathrm{~h} 6$ belonged to the same group and $\mathrm{h} 7, \mathrm{~h} 8$ belonged to the other group. The results of PLS-DA model can be used to determine the important features of $X$ which can determine the class membership of $Y$. In order to obtain this important information, a VIP-based feature selection index, FSI ${ }_{j}^{V I P}$ is calculated as follows [37],

$$
F S I_{j}^{V I P}=\frac{N \sum_{i=1}^{A} w_{i j}{ }^{2} R S S_{i}}{R S S_{T}} \quad j=1,2, . ., N,
$$

Table 3. R2X and R2Y Values of partial least squares discriminatory (PLS-DA) model.

\begin{tabular}{ccccc}
\hline Component & R2X & R2Xcum & R2Y & R2Ycum \\
\hline t1 & 0.260 & 0.260 & 0.152 & 0.152 \\
t2 & 0.149 & 0.410 & 0.015 & 0.167 \\
\hline
\end{tabular}




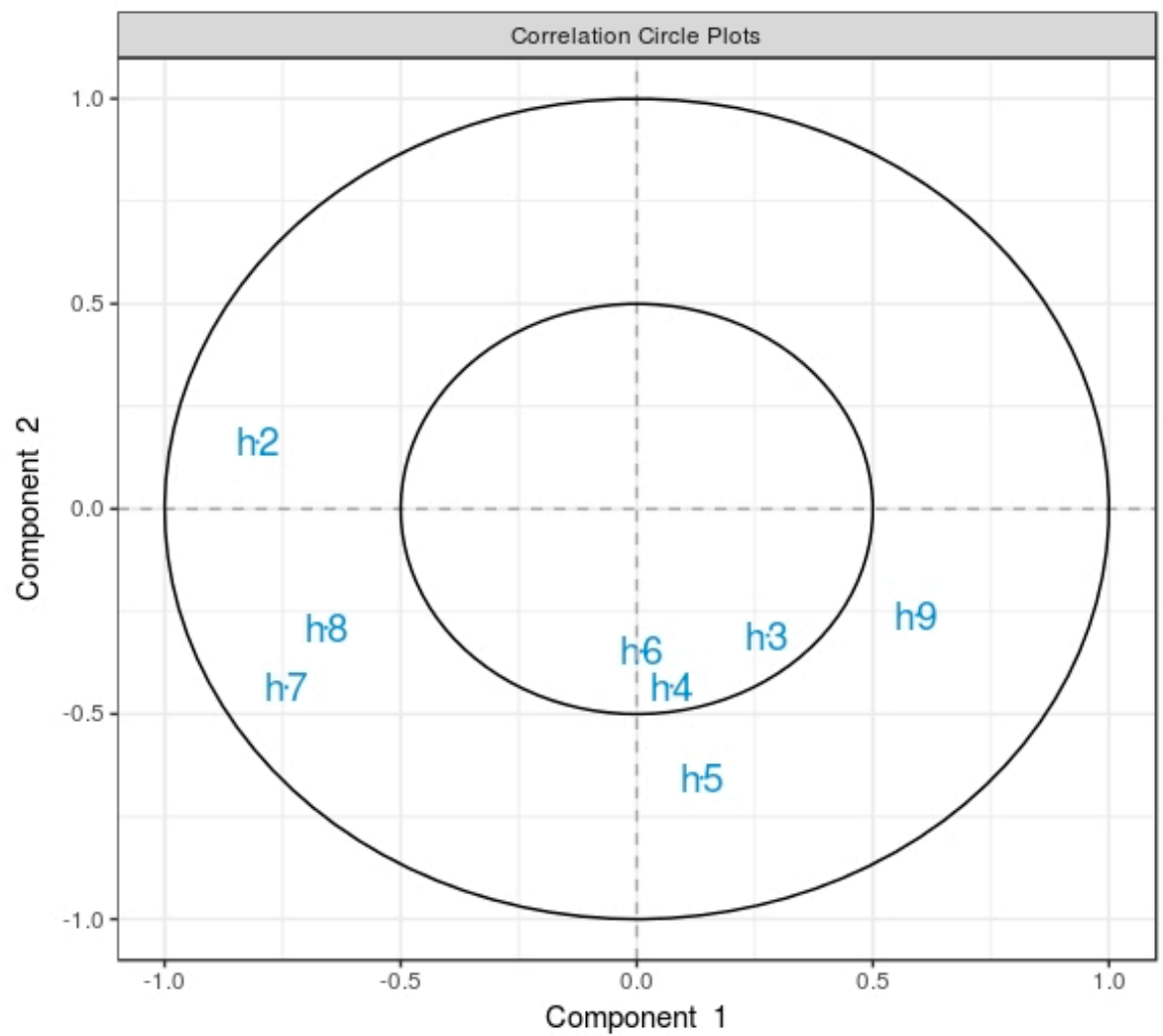

Figure 4. Variables plot of the PLS-DA model.

The Model VIP of PLS-DA model was shown in Table 4.

Table 4. Model variable on projection (VIP) of PLS-DA model.

\begin{tabular}{cccc}
\hline & Component 1 & Component 2 & Model VIP \\
\hline h2 & 1.846 & 1.783 & 1.783 \\
h3 & 0.439 & 0.429 & 0.429 \\
h4 & 0.094 & 0.238 & 0.238 \\
h5 & 0.278 & 0.509 & 0.509 \\
h6 & 0.043 & 0.107 & 0.107 \\
h7 & 1.371 & 1.406 & 1.406 \\
h8 & 1.129 & 1.101 & 1.101 \\
h9 & 1.073 & 1.055 & 1.055 \\
\hline
\end{tabular}

According to Cho et al. (2008), we selected the independent variables with Model VIP values larger than 1 as the important ones, which include h2, h7, h8 and h9 [37].

\subsection{OPLS-DA Model}

The study also utilized the orthogonal partial least squares (OPLS) model to make the classification analysis. Trygg and Wold (2002) apply the orthogonal projection to OPLS algorithm to construct the variations of the predictors correlated and orthogonal to the response [38].

Gennebäck et al. (2013) stipulates the OPLS-DA model. The OPLS model is utilized to seek for a variation in matrix $X$, which is correlated with the response matrix $Y$. The categorical response matrix is thus created. In the OPLS model, the variation of $Y$ is used to divide the variation of $X$ into three 
parts: the systematic variation of $X$ orthogonal to $Y$, the systematic variation of $X$ correlated to $Y$ and non-systematic variation of $X$. The OPLS-DA model is shown in Equation (5) [39]:

$$
X=T_{P} P_{p^{T}}+T_{O} P_{O^{T}}+e
$$

where $T_{p}$ and $P_{P}$ indicate the $Y$ orthogonal scores and loadings. The residual of $X$ is expressed by $e$. The study applied the "ropls" package of the $R$ language to make the OPLS-DA analysis. The results of OPLS-DA analysis are shown Figure 5.
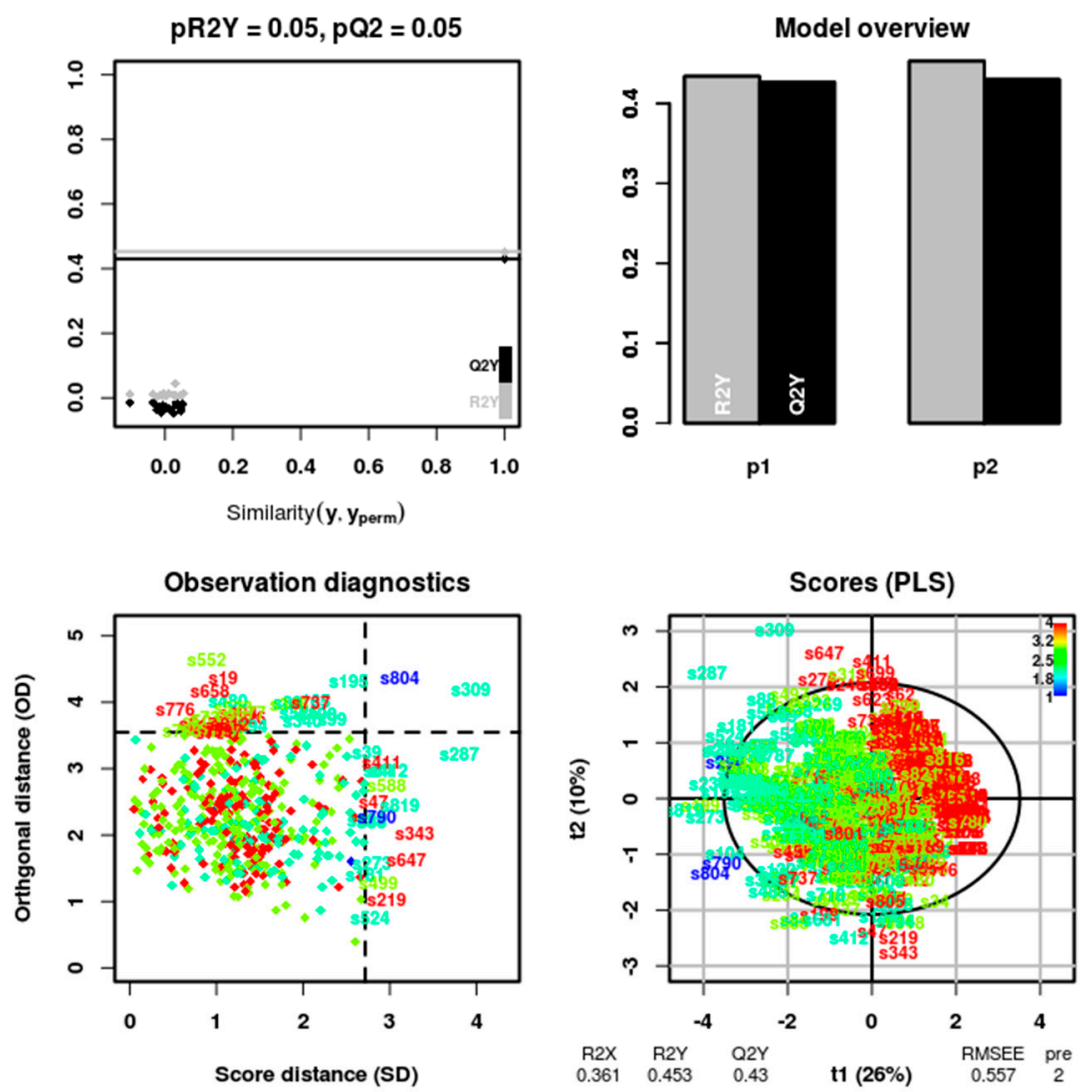

Figure 5. Results plot of the orthogonal partial least squares discriminatory (OPLS-DA) model.

According to Figure 4, the top-left of the plot means that R2Y and Q2Y of the model are compared with the corresponding values obtained after random permutation of the $Y$ response. The R2Y value was larger than that of PLS-DA model. The bottom-right of the plot showed the number of components $(=2)$ and the R2X value was 0.361 which was larger than that of PLS-DA model.

The study also obtained the relationship plot of independent variables and four categories (satisfaction levels of h1) from the "ropls" package of R language as Figure 6.

The relationship plot among the independent variables and four categories (satisfaction levels of h1) in the first two components was shown as Figure 6. It indicated that only h2, h3, h5, h7, h8 and h9 had a relationship with the four categories of satisfaction level h1.

According to Figure 7, h7 and h8 belonged to the same group, while h3, h4, h5 and h6 belonged to the other group. As for the four categories of the h1 (satisfaction level), the satisfaction level 1 and 3 belonged to the same group, while their impacts were quite limited on the components $t 1$ and $t 2$.

The study also utilized the "mixOmics" package of $\mathrm{R}$ language to apply the OPLS-DA model in order to make the classification as Figure 8. 


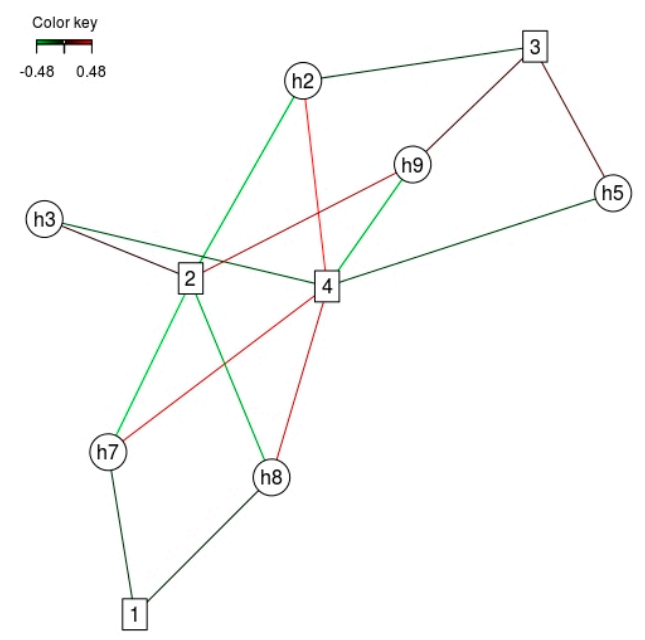

Figure 6. Relationship plot of the OPLS-DA model.

\section{Circle of Correlations on $t_{1}, t_{2}$}

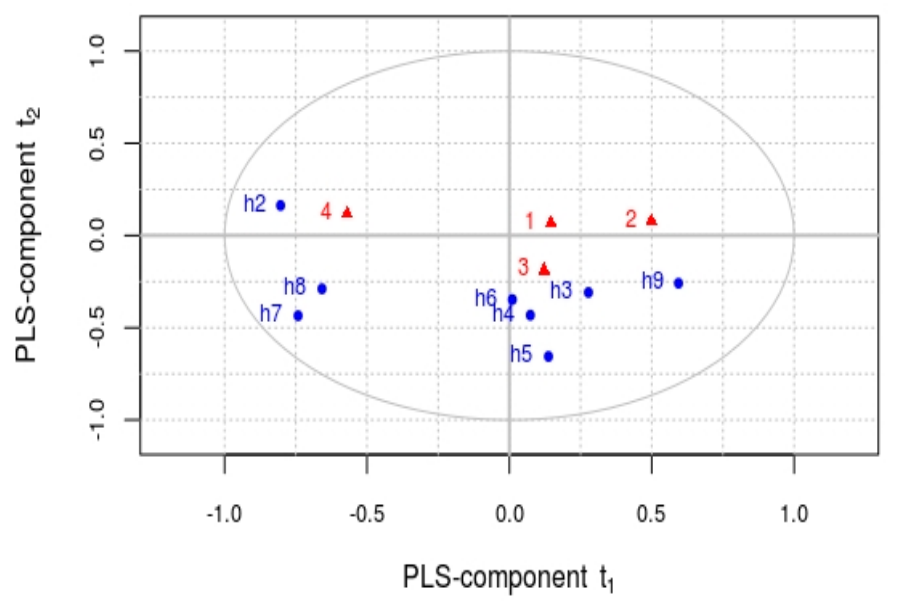

Figure 7. Relationship plot in the first two components of the OPLS-DA model.

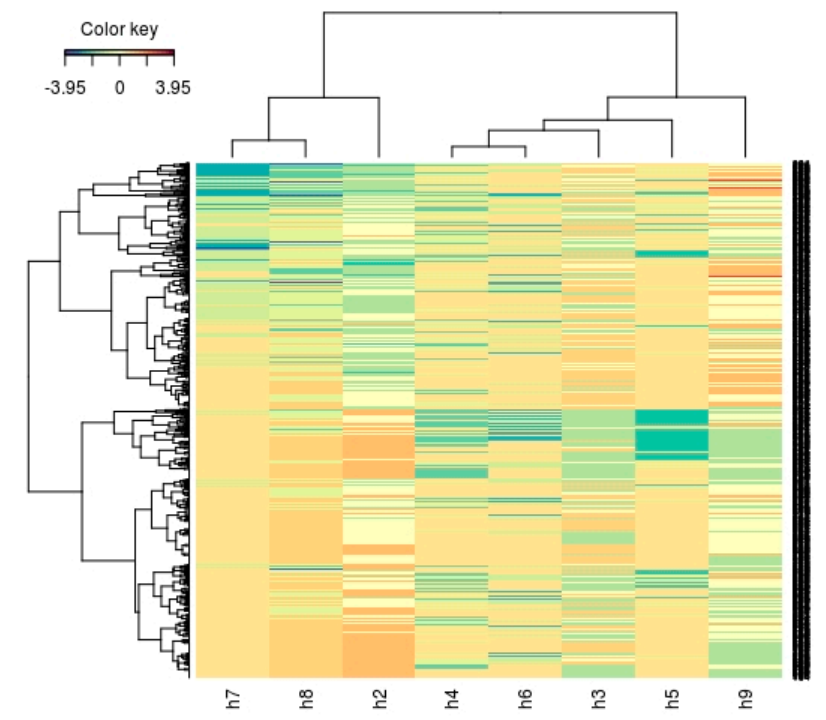

Figure 8. Classification results of the OPLS-DA model. 
According to the Figure 8, the major nodes in the classification results were h7, h8 and h2.

\section{Discussion}

The PLS-DA model and the OPLS-DA model are widely applied in medical research. The study is the first research which utilizes the two models in order to gather the factors with the major impacts on Taiwanese civilians' satisfaction with the central government, which is closely related to political sustainability. The major findings of our research are as follows:

(i) First, the study constructed the PLS-DA model and made the principal component analysis. Since the results of PLS-DA principal component analysis chose one component to represent all independent variables, it implied that $\mathrm{h} 2, \mathrm{~h} 7, \mathrm{~h} 8$ had positive relationships with the dependent variable h1.

(ii) The variables plot of PLS-DA model indicated that $\mathrm{h} 3 \mathrm{~h}, \mathrm{~h} 4 \mathrm{~h} 6 \mathrm{belonged}$ to the same group and $\mathrm{h} 7$, $\mathrm{h} 8$ belonged to the other group. The PLS-DA model also made the model VIP analysis and found that h2, h7, h8 and h9 had larger impacts on h1.

(iii) In order to obtain more information and improve the predictive performance of our model, the study used the OPLS-DA model to make the analysis. We found that the R2Y and Q2Y values were larger than that of the PLS-DA model. This means that the OPLS-DA model had better predictive performance. The relationship plot of the OPLS-DA results implied that only $\mathrm{h} 2, \mathrm{~h} 3, \mathrm{~h} 5, \mathrm{~h} 7, \mathrm{~h} 8$ and $\mathrm{h} 9$ had the relationship with the four categories of satisfaction level of $\mathrm{h} 1$. The independent variables $\mathrm{h} 7 \mathrm{and} \mathrm{h} 8 \mathrm{had}$ the relationship with the first, second and fourth satisfaction level of $\mathrm{h} 1$, while $\mathrm{h} 2$ and $\mathrm{h} 9$ had the links with the second, third and fourth satisfaction level of h1, h3 and h9 had the links with the second and fourth satisfaction level of h1. h5 was related to the third and fourth satisfaction level of h1. It can be induced that the Taiwanese civilians' lowest satisfaction level with the central government relates to the central government's modus operandi on food safety (h7) and the twelve years primary education reform (h8).

(iv) The study also utilized the OPLS-DA model to make the classification analysis by using $\mathrm{h} 1$ as the target variable and found the major nodes in the classification results were $\mathrm{h} 7, \mathrm{~h} 8 \mathrm{and} \mathrm{h} 2$.

(v) As far as our research models are concerned, we conclude that the satisfaction with the integrity performance of the central government (h2), satisfaction with the central government's modus operandi on food safety (h7), satisfaction with the central government's policies on the twelve years primary education reform (h8) influence the Taiwanese civilians' satisfaction with the central government, which is closely related to political sustainability. It can be inferred from the results of the study that the major factors which affect the civilians' satisfaction with the central government are inclusive of the levels of the civilians' satisfaction with the educational and food safety policies and the central government's integrity. However, the Sunflower Movement only has a limited impact. Taiwan's experience can be the example for other governments because the temporary social movement would not definitely influence the support of the central government, and it can only affect the formulation of the emerging political power [40]. It also suggests that the Taiwanese government needs to improve its governance ability and public opinion feedback in order to achieve the political sustainability.

\section{Conclusions}

The study used the PLS-DA and OPLS-DA models to explore the factors which affected Taiwanese people's satisfaction with the central government in 2014. The study found that Taipei residents' satisfaction with the central government related to their views toward the integrity performance of the central government, and their views toward government's policies of the food safety and educational reform. It implies that Taiwanese government needs to improve its governance ability and public opinion feedback in order to achieve the political sustainability. Taiwan's experience can offer the 
example of political sustainability under the circumstances of the changing public opinion, which can be of interest to other governments.

Acknowledgments: The authors would like to show their gratitude for the Macau Foundation Research Fund and the Faculty Research Grant of Macau University of Science and Technology.

Author Contributions: All authors make the equal contribution to this article.

Conflicts of Interest: The authors declare no conflict of interest.

\section{References}

1. Lauridsen, L.S. Governance and Economic Transformation in Taiwan: The Role of Politics. Dev. Policy Rev. 2014, 32, 427-448. [CrossRef]

2. Borrás, S. System of innovation theory and the European Union. Sci. Public Policy 2004, 31, 425-433. [CrossRef]

3. Schmitz, H.; Cassiolato, J. (Eds.) Hi-Tech for Industrial Development: Lessons from the Brazilian Experience in Electronics and Automation; Routledge: London, UK, 1992.

4. Patashnik, E. After the public interest prevails: The political sustainability of policy reform. Governance 2003, 16, 203-234. [CrossRef]

5. Navarro-Galera, A.; Ruiz-Lozano, M.; Tirado-Valencia, P.; Ríos-Berjillos, A.D.L. Promoting Sustainability Transparency in European Local Governments: An Empirical Analysis Based on Administrative Cultures. Sustainability 2017, 9, 432. [CrossRef]

6. Patashnik, E. Reforms at Risk: What Happens after Major Policy Reforms Are Enacted; Princeton University Press: Princeton, NJ, USA, 2008; ISBN 9781400828852.

7. Ayre, G.; Callway, R. (Eds.) 2005 Governance for Sustainable Development; Earthscan: London, UK, 2005.

8. Holden, E.; Linnerud, K.; Banister, D. The imperatives of sustainable development. Sustain. Dev. 2017, 25, 213-226. [CrossRef]

9. Leal Filho, W.; Platje, J.; Gerstlberger, W.; Ciegis, R.; Kääriä, J.; Klavins, M.; Kliucininkas, L. The role of governance in realising the transition towards sustainable societies. J. Clean. Prod. 2016, 113, 755-766. [CrossRef]

10. Weaver, J.H.; MT Kusterer, K. Achieving Broad-Based Sustainable Development: Governance, Environment, and Growth with Equity; No. P01 151; Kumarian Press: Stirling, VA, USA, 1997.

11. Foret, M.; Klusáček, P. The importance of the partnership and cooperation in the regional development exampled on Znojmo region. Acta Univ. Agric. Silvicult. Mendel. Brunen. 2014, 59, 79-86. [CrossRef]

12. Mälkiä, M.; Anttiroiko, A.V.; Savolainen, R. (Eds.) eTransformation in Governance: New Directions in Government and Politics; IGI Global: Hershey, PA, USA, 2004.

13. Fournier, V. Escaping from the economy: The politics of degrowth. Int. J. Sociol. Soc. Policy 2008, 28, 528-545. [CrossRef]

14. Holzer, M.; Kloby, K. Sustaining citizen-driven performance improvement: Models for adoption and issues of sustainability. Innov. J. Public Sect. Innov. J. 2005, 10, 521-541.

15. Reddel, T.; Woolcock, G. From consultation to participatory governance? A critical review of citizen engagement strategies in Queensland. Aust. J. Public Adm. 2004, 63, 75-87. [CrossRef]

16. Li, Y.; Beeton, R.J.S.; Sigler, T.; Halog, A. Modelling the transition toward urban sustainability: A case study of the industrial city of Jinchang, China. J. Clean. Prod. 2016, 134, 22-30. [CrossRef]

17. Demmke, C.; Moilanen, T. Effectiveness of Good Governance and Ethics in Central Administration: Evaluating Reform Outcomes in the Context of the Financial Crisis. 2011. Available online: https:/ / www.oeffentlicherdienst.gv.at (accessed on 8 September 2014).

18. Hsieh, J.; Niou, E. Salient issues in Taiwan's electoral politics. Elect. Stud. 1996, 15, 219-235. [CrossRef]

19. Chen, P. Lessons from Taiwan's Economic Development. Orbis 2016, 60, 515-530. [CrossRef]

20. Bouckaert, G.; Van de Walle, S.; Kampen, J.K. Potential for comparative public opinion research in public administration. Int. Rev. Adm. Sci. 2005, 71, 229-240. [CrossRef]

21. Stipak, B. Local governments' use of citizen surveys. Public Adm. Rev. 1980, 40, 521-525. [CrossRef]

22. Licari, M.; McLean, W.; Rice, T. The condition of community streets and parks: A comparison of resident and nonresident evaluations. Public Adm. Rev. 2005, 65, 360-368. [CrossRef] 
23. Van Ryzin, G.G. Pieces of a puzzle: Linking government performance, citizen satisfaction, and trust. Public Perform. Manag. Rev. 2007, 30, 521-535. [CrossRef]

24. Lin, T.B.; Wang, L.Y.; Li, J.Y.; Chang, C. Pursuing quality education: The lessons from the education reform in Taiwan. Asia-Pac. Educ. Res. 2014, 23, 813-822. [CrossRef]

25. Hallinger, P. Making education reform happen: Is there an Asian way? Sch. Leadersh. Manag. 2010, 30, 401-418. [CrossRef]

26. Yang, J.; Hauser, R.; Goldman, R.H. Taiwan food scandal: The illegal use of phthalates as a clouding agent and their contribution to maternal exposure. Food Chem. Toxicol. 2013, 58, 362-368. [CrossRef] [PubMed]

27. Tsai, H.J.; Chen, B.H.; Wu, C.F.; Wang, S.L.; Huang, P.C.; Tsai, Y.C.; Chen, M.L.; Ho, C.K.; Hsiung, C.A.; $\mathrm{Wu}$, M.T. Intake of phthalate-tainted foods and microalbuminuria in children: The 2011 Taiwan food scandal. Environ. Int. 2016, 89, 129-137. [CrossRef] [PubMed]

28. Rowen, I. Inside Taiwan's Sunflower Movement: Twenty-Four Days in a Student-Occupied Parliament, and the Future of the Region. J. Asian Stud. 2015, 74, 5-21. [CrossRef]

29. Ho, M. Occupy congress in Taiwan: Political opportunity, threat, and the Sunflower Movement. J. East Asian Stud. 2015, 15, 69-97. [CrossRef]

30. Doherty, B.; de Geus, M. (Eds.) Democracy and Green Political Thought: Sustainability, Rights, and Citizenship; Psychology Press: Devon, UK, 1996.

31. Joshi, D.K.; Hughes, B.B.; Sisk, T.D. Improving governance for the post-2015 sustainable development goals: Scenario forecasting the next 50 years. World Dev. 2015, 70, 286-302. [CrossRef]

32. Ivezić, Ž.; Connolly, A.J.; VanderPlas, J.T.; Gray, A. Statistics, Data Mining, and Machine Learning in Astronomy: A Practical Python Guide for the Analysis of Survey Data; Princeton University Press: Princeton, NJ, USA, 2014; pp. 3-4.

33. Eriksson, L.; Hermens, J.L.; Johansson, E.; Verhaar, H.J.; Wold, S. Multivariate analysis of aquatic toxicity data with PLS. Aquat. Sci.-Res. Bound. 1995, 57, 217-241. [CrossRef]

34. Huang, C. Taiwan's Election and Democratization Study, 2012-2016 (III): The Survey of the Nine-in-One Local Elections in 2014: 2012-2016 (III) (TEDS2014) (E10137); Available from Survey Research Data Archive; Academia Sinica: Taipei, Taiwan, 2016.

35. Mevik, B.; Wehrens, R. The pls Package: Principal Component and Partial Least Squares Regression in R. J. Stat. Softw. 2007, 18, 1-23. [CrossRef]

36. Heim, R.H.J.; Jürgens, N.; Große-Stoltenberg, A.; Oldeland, J. The effect of epidermal structures on leaf spectral signatures of ice plants (Aizoaceae). Remote Sens. 2015, 7, 16901-16914. [CrossRef]

37. Cho, H.W.; Kim, S.B.; Jeong, M.K.; Park, Y.; Miller, N.; Ziegler, T.; Jones, D. Discovery of metabolite features for the modelling and analysis of high-resolution NMR spectra. Int. J. Data Min. Bioinform. 2008, 2, 176-192. [CrossRef] [PubMed]

38. Trygg, J.; Wold, S. Orthogonal projections to latent structures (O-PLS). J. Chemom. 2002, 16, 119-128. [CrossRef]

39. Gennebäck, N.; Malm, L.; Hellman, U.; Waldenström, A.; Mörner, S. Using OPLS-DA to find new hypotheses in vast amounts of gene expression data-Studying the progression of cardiac hypertrophy in the heart of aorta ligated rat. Gene 2013, 522, 27-36. [CrossRef] [PubMed]

40. Lo, V.H.; Wei, R.; Lu, H.Y. Issue Importance, Third-Person Effects of Protest News, and Participation in Taiwan's Sunflower Movement. J. Mass Commun. Q. 2017, 94, 682-702. [CrossRef]

(c) 2018 by the authors. Licensee MDPI, Basel, Switzerland. This article is an open access article distributed under the terms and conditions of the Creative Commons Attribution (CC BY) license (http:/ / creativecommons.org/licenses/by/4.0/). 